\title{
LGBTIQA+ Learners in New Zealand Schools
}

New Zealand Journal of Teachers' Work, Volume 15, Issue 2, 94-99, 2018

\author{
HOWIE BRUCE \\ JENNY HORSLEY \\ Victoria University of Wellington
}

\section{INTRODUCTION}

The New Zealand Curriculum (2007) states that all students have the right to learn in an environment that is inclusive and safe. Teachers in New Zealand are responsible for upholding these and many other values, ensuring that each student's "unique set of experiences, abilities and interests, and differences in how they learn" (Ministry of Education, 2017a, para 2) are accommodated in the classroom. This research overview considers New Zealand articles on Lesbian, Gay, Bisexual, Transgender, Intersex, Queer and Allied (LGBTIQA+) students. Moreover, it identifies the importance of LGBTIQA+ students receiving the support they need to deter depressive thoughts and bullying. Consideration is given to what schools and teachers could do to develop inclusive classrooms for this group of diverse learners, thus supporting these students to reverse their negative experiences of schooling.

In line with the Ministry of Education (2017b) the broad and encompassing term of 'LGBTIQA+' is used here to describe non heterosexual students. The charitable organisation Rainbow Youth (2017) uses the label LGBT, with the phrases 'queer' and 'gender diverse' used frequently. The Ministry of Education also uses phrases such as 'gender or sexually diverse'. This review has not restricted the literature to any one sub group, thus LGBTIQA+ is preferred.

Awareness of the rights of those groups with the label LGBTIQA+ is a recent development in New Zealand's history and society. For example, only as recently as 1986, was homosexuality decriminalised (New Zealand History, n.d.). Even more recently, the Marriage Amendment Act, 2013 defined marriage to mean: ".. the union of 2 (sic) people, regardless of their sex, sexual orientation, or gender identity", thus making it possible for same sex as well as opposite-sex couples to marry (Parliamentary Counsel Office, n.d.). Given that this Act accords recognition of equal status between same-sex or heterosexual couples, it could be expected that students who are gay or those identified within the term LGBTIQA+, will also have equal status in other facets of life in relation to their heterosexual peers. This would seem especially important, given the purpose statement of the New Zealand Ministry of Education (2017c) that avows: "We shape an education system that delivers equitable and excellent outcomes" (para. 2). It would appear, however, that for LGBTIQA+ students in New Zealand schools there is little evidence to suggest they are currently recipients of equitable and excellent outcomes. 
Research focused on diversity has tended to include Māori or Pasifika students; those students identified on the autistic spectrum, and students whose needs are specific to their learning or behaviour (see for example Bishop, Berryman, Cavanagh, \& Teddy, 2009; Thabrew \& Eggleston, 2017; Tuagalu, Cram, Phillips, \& Sauni, 2014). There is however scant research in relation to LGBTIQ+ learners, or appropriate strategies provided to teachers to support this group of learners to ensure the Ministry of Education meets its purpose of shaping "an education system that delivers equitable and excellent outcomes" (Ministry of Education, 2017c, para. 2).

The in-school programmes discussed in this research overview as well as others offered by Non-Government Organisations offer help in understanding diversity and respect for LGBTIQ+ learners and assist in educating students on the topic of diversity. But, unlike many of the articles describing individualised learning programmes for students with 'other' needs (for example, Māori or Pasifika students; students with ASD), they do not offer programmes or long term guidance to teachers.

\section{LITERATURE}

Clark et al., (2013) identified the paucity of research relating to LGBTIQA+ learners, finding that transgender research is often merged with gay, lesbian and bisexual research. Their study involving students from 91 high schools found that of the 8,166 respondents, $94.7 \%$ identified as non-transgender, $1.2 \%$ identified as transgender, $1.7 \%$ did not understand the question and $2.5 \%$ reported being unsure about their gender. Further findings indicated that one in five transgender students perceived they were either bullied or in fear of being bullied. Forty percent of transgender students reported feelings of depression and suicide. These feelings were also reported by students in other studies, with Denny et al. (2016) hypothesising early in their study that they would find a relationship between non heterosexual students, suicidal thoughts and depression.

These researchers, who comprised a range of academics from psychology, paediatrics and education, also hypothesised that their study would reveal both supportive and non-supportive school environments for heterosexual, bisexual and homosexual students (Denny et al., 2016). They used data from 2007 to identify suicide, depressive thoughts and bullying in non-heterosexual students. Additional submissions from teachers were sought to ascertain their views of the safety of these students in schools. Results showed a relationship between a supportive gay and bisexual educational environment and a lowered risk of suicide and depression. The findings identified that those schools deemed to be supportive toward anti-bullying and gay and bisexual students, lessened the likelihood of these groups of students experiencing bullying. Students who identified as bisexual had the highest rates of suicide attempts per annum at $31.7 \%$. Homosexual students' rates were high also at $13.9 \%$ and heterosexual students were at $4.0 \%$ (Denny et al., 2016). The researchers suggest this indicates that teachers and schools have a strong responsibility to these diverse learners to ensure they are cared for, and bullying and discrimination is expunged at the earliest stages possible.

Another New Zealand based project aimed to assess students' feelings towards, before, and after a Rainbow Youth workshop on understanding sexual 
and gender minorities (Burford, Lucassen \& Hamilton, 2017). By studying the reception of students to courses and workshops such as those run by Rainbow Youth the researchers endeavoured to understand whether or not providing more workshops could improve the outlook for LGBTIQA+ students in New Zealand. They also considered whether these workshops could help nonLGBTIQA+ students become more accepting and compassionate towards their LGBTIQA+ peers. These academics wanted to identify whether or not students found workshops on gender diversity helpful in reducing understanding of sexual minorities, and therefore reducing bullying (Burford et al., 2017). An interesting facet of this study was the diversity represented in the wide range of participants. This included 236 students from various schools in the Auckland region, with participants aged between 12 and 15 years of age, and a range of ethnic groups that included Māori (13.9\%), Asian (11.4\%), Pacific (66,2\%) and European (1.3\%).

Most participants (80\%) in the Burford et al. (2017) study believed a course such as the one organised by Rainbow Youth, would reduce bullying in their school and specifically, the bullying towards LGBTIQA+ students. The findings identify that while students may want to be more inclusive and caring towards LGBTIQA+ students, they do not necessarily know how to do this. This literature identifies an opportunity for New Zealand academics and educators to promote workshops in diversity and inclusiveness, to advocate for a bullyingfree culture in New Zealand schools.

Hemi and Mortlock (2017) describe an action research project focussed on improved outcomes for LGBT students in one New Zealand secondary school. This study aimed to enhance the interpersonal and physical environments of "students with diverse gender identities and sexual orientations" (p. 99). Recommendations include consideration of a school uniform that is more inclusive; safe space for these students to meet regularly; physical spaces (e.g. school walls) to include LGBT students' work; and, reducing bullying, while educating all students about LGBT and ways in which they can help to reduce any possible discrimination or stigma.

In addition to identifying the role of courses that aim to educate and inform, the New Zealand Ministry of Education (n.d.) provides suggestions for schools and teachers in their role of supporting LGBTIQA+ students. Although these do not appear to be evidence-based, the Ministry recommends:

- Developing inclusive classrooms

- Using language to affirm diversity

- Making LGBTIQA+ content and themes visible across the curriculum

- Using targeted programmes to facilitate opportunities for healthy discussion about sexuality, gender identity and diversity

- Planning and delivering sexuality and gender education within the New Zealand Curriculum, years 1 to 6 
- Planning and delivering sexuality and gender education within the New Zealand Curriculum, years 7 to 13. (para. 7)

Further delving into this material reveals resources that link to other groups supportive of education around diversity, including The Rainbow Trust and the Safe School Coalition in Australia (Ministry of Education, n.d.). Two key ideas to emerge from these and other resources, is the need for awareness and education-findings that were also identified in the studies that have been discussed in this research overview.

\section{CONCLUSION}

The studies discussed in this research overview have found that New Zealand schools contain students who identify as transgender, gay and bisexual, thereby falling under the umbrella of students who are described as LGBTIQA+ (Clarke et al., 2013; Denny et al., 2016). All New Zealand teachers have an obligation to investigate classroom practices and approaches that create inclusive and safe environments, as charged by the Ministry of Education (2017b). This obligation extends to the one in five transgender students who feel bullied and the $40 \%$ of bisexual students who feel suicidal or depressed (Clarke et al., 2013). One possible strategy to address this concern emerged from the study considering the effect of workshops to educate students about LGBTIQA+ students (Burford et al., 2017). Findings suggest that students are willing to learn about these topics; they want to form a rational understanding of LGBTIQA+ students and, that workshops such as those provided by Rainbow Youth, provide this opportunity for positive education. Sites such as the one provided by the Ministry of Education (n.d.), will support teachers to identify strategies they can employ to educate their learners about LGBTIQA+, and to create awareness around the theme of 'diversity'.

The parent of a child with 'special needs' wrote that: "Inclusive education is essential because if you're not being included, you're excluded" (Tenacious, n.d.). Clearly, the experiences of LGBTIQA+ students identified in these described research projects, reveals not only exclusion, but a link between school culture, bullying and LGBTIQA+ students in New Zealand (Burford et al., 2017; Clarke et al, 2013). Research also indicates that non-LGBTIQA+ students want to be better informed and educated about these learners (Burford et al., 2017; Hemi \& Mortlock, 2017). Clearly, the research identifies an opportunity for New Zealand schools and teachers to encourage and teach inclusiveness and diversity to learners, thereby creating a thoughtful and purposely designed learning environment in which LGBTIQA+ can be assured of equitable and excellent outcomes. 


\section{REFERENCES}

Bishop, R., Berryman, M., Cavanagh, T., \& Teddy, L. (2009). Te kotahitanga: Addressing educational disparities facing Māori students in New Zealand. Teaching and Teacher Education, 25(5), 734-742.

Burford, J., Lucassen, F. G., \& Hamilton T. (2017). Evaluating a gender diversity workshop to promote positive learning environments. Journal of LGBT Youth, 14:12, 211-227. doi https://doi.org/10.1080/19361653.2016.1264910

Clark, T., Lucassen, F.G., Bullen, P., Denny, S., Fleming, T., Robinson, E., \& Rossen, F. (2013). The health and wellbeing of transgender high school students: Results from the New Zealand adolescent health survey (Youth'12). Journal of Adolescent Health, 55, 93-99. Retrieved from www.jahonline.org.

Denny, S., Lucassen F.G., Stuart, J., Fleming, T., Bullen, P., Peiris-John, R., Utter, J. (2016). The association between supportive high school environments and depressive symptoms and suicidality among sexual minority students. Journal of Clinical Child \& Adolescent Psychology, 45:3, 248-261. doi https://doi.org/10.1080/15374416.2014.958842

Hemi, W., \& Mortlock, A. (2017). On the periphery or at the centre?: Ideas for improving the physical and interpersonal environments for lesbian, gay, bi-sexual, and trans-sexual/gender students at a New Zealand secondary school. New Zealand Journal of Teachers' Work, 14(2), 99-113.

Ministry of Education (2007). The New Zealand Curriculum. Retrieved from http://nzcurriculum.tki.org.nz/The-New-Zealand-Curriculum

Ministry of Education (2017a). Designing inclusive learning environments. Retrieved from https://www.education.govt.nz/news/designing-inclusivelearning-environments/

Ministry of Education (2017b). Inclusive Education Guide for schools, $L G B T I Q A+$ students. Retrieved from http://inclusive.tki.org.nz/guides/category/lgbtiqa/

Ministry of Education (2017c). About us. Retrieved from https://education.govt.nz/ministry-of-education/our-role-and-our-people/

Ministry of Education (n.d.) Inclusive schools: Supporting LGBTIQA+ students. Retrieved from http://inclusive.tki.org.nz/guides/lgbtiqa/

New Zealand History (n.d.). Homosexual law reform. Retrieved from https://nzhistory.govt.nz/culture/homosexual-law-reform/homosexual-lawreform

Parliamentary Counsel Office, (2018). New Zealand Legislation: Marriage Act 155 (Amended). Retrieved from http://www.legislation.govt.nz/act/public/1955/0092/latest/whole.html\#DL M292032

Rainbow Youth (2017). Retrieved from www.ry.org.nz 
Tenacious, R. K. (n.d.) Why is inclusion education essential? Retrieved from https://inclusiveteach.com/2018/04/14/why-is-inclusive-educationessential/

Thabrew, H., \& Eggleston, M. (2017). Spectrum of care: Current management of childhood autism spectrum disorder (ASD) in New Zealand. Australasian Psychiatry, 1039856217716290.

Tuagalu, C., Cram, F., Phillips, H., \& Sauni, P. (Eds.). (2014). Māori and Pasifika higher education horizons. Emerald Group Publishing. https://www.emeraldinsight.com/doi/pdfplus/10.1108/S1479364420140000015004 